\title{
Intuition Isn't Enough for Entrepreneurs
}

\author{
Sharon Alvarez (University of Pittsburgh) \\ Kathleen Allen (University of Southern California) \\ Lars Oddsson (U of MN \& RxFunction Inc.)
}

KEYWORDS: Innovation, Marketing, Product

Development.

Entrepreneurial legends like Steve Jobs -- who created blockbuster products without asking anyone if they wanted them - anticipated the market. Many other entrepreneurs have great ideas that never amount to anything. While it would be easy to take the Steve Jobs example and suggest that the most successful entrepreneurs are superheroes with X-ray vision, we know from our research that these apparent acts of intuition are the result of human beings who know how to listen to the market, at times anticipate the market, experiment, make mistakes, sometimes change directions, and sometimes persist with a course of action. In this discussion, the University of Minnesota's Lars Oddsson, University of Denver's Sharon Alvarez and USC's Kathleen Allen talk about the interplay between action and inspiration. 